\title{
Vendor Selection and Supply Quotas Determination by Using a New Multi- Objective Programming Method Based on Cooperative Game Theory
}

\author{
Tunjo Perić
}

Faculty of Economics and Business Zagreb, University of Zagreb, Croatia

\section{Abstract}

Background: Vendor selection and supply quotas determination is one of the most important issues in the purchasing process in manufacturing. In many situations to solve this problem it is necessary to use the operations research methods. Objectives: This paper proposes a new methodology for vendor selection and determination of supplied quotas. The work investigates the problem of flour purchase by a company that manufactures bakery products. Methods/Approach: The problem is solved by using the model that combines a revised weighting method, and a multiple objective programming method based on game theory. The revised weighting method is used to determine the objective function coefficients, and a multiple objective programming method is used to select vendors and to determine supply quotas from the selected vendors. For selection of vendors and determination of quantities supplied by individual vendors three complex criteria are used: (1) purchasing costs, (2) product quality, and (3) vendor reliability. Results: The proposed methodology has numerous strengths, such as an efficient reduction of complex criteria functions to simple ones and efficient using of a new multiple objective programming methods based on cooperative game theory. Conclusions: The main advantage of the proposed approach is its efficiency and simplicity.

Keywords: cooperative game theory; multiple objective programming; revised weighting method; vendor selection

JEL classification: C7

Paper type: Research article,

Received: Aug 18, 2015

Accepted: Feb 15, 2016

Citation: Perić, T. (2016), "Vendor Selection and Supply Quotas Determination by Using a New Multi-Objective Programming Method Based on Cooperative Game Theory", Business Systems Research, Vol. 7, No. 1, pp. 104-118.

DOI: 10.1515/bsrj-2016-0008

Acknowledgments: This paper has been fully supported by Croatian Science Foundation under the project STRENGTHS Number 9402. 


\section{Introduction}

The problem of vendor selection and supply quotas determination is the key element in the purchasing process in manufacturing. The purchasing company must decide which vendors they should contract with and they must determine the appropriate order quantity for each vendor selected.

In this paper we are discussing the supplier selection and supply quotas determination problem for the companies which purchase flour for producing bread and bakery products. Before the selection process starts the decision makers (DM's) should define the minimal and maximal number of the suppliers from which they would purchase the flour, and the maximal quantity purchased from an individual vendor. The proposed methodology combines two methods used in operational researches: revised weighting method and a new multiple objective linear programming methods (in the text called 'MP method') (Matejaš, Perić, 2014). The revised weighting method is used to determine the coefficients of complex criteria functions (quality and reliability). Coefficients determined in this way present the coefficients of the objective functions in multiple objective integer linear programming (MOILP) model providing the final vendor selection and the quantity supplied from a particular vendor. We are using the MOILP model with three objective functions: (1) purchasing costs, (2) product quality, and (3) vendor reliability. An idea of cooperative game theory helps DMs in the process of the MOILP model solving to find the preferred solution. In the MOILP model we are using the following constraints: (1) the total demand, (b) the minimal and maximal number of vendors and (3) the limitations of vendor capacities.

Vendor selection and supplied quotas determination is an important issue dealt with by numerous researchers. Great efforts have been made to define appropriate models for vendor selection and determination of supply quotas from the selected vendors and to apply the adequate methods to solve such models.

The literature dealing with vendor selection uses various methods. Among the numerous studies dealing with this topic we will mention some more important ones. A large number of papers include AHP method in combination with the multiobjective linear programming methods. Thus for instance Ghodsypour and O'Brien (1998) use the AHP method in combination with linear programming. Ge Wang, Samuel and Dismekes (2004) use the AHP and goal programming. Kumar, Shankar and Yadav (2008) use the AHP method and fuzzy linear programming, while Kumar, Vrat and Shankar $(2004,2005)$ use only fuzzy goal programming for that purpose. Perić, Babić and Veža (2013) use AHP and fuzzy linear programming to solve the vendor selection and supplied quotas determination problem in a bakery. A smaller number of papers combine revised weighting method and multi objective linear programming methods. Perić and Babić (2009) solve the vendor selection and supplied quotas determination problem by using the revised weighting method and fuzzy multi-criteria programming. However, there are no methodologies which simultaneously use revised weighting method and the new MOILP based on the cooperative game theory to solve vendor selection and supply quotas determination problem.

The main idea of the study in this paper is to create a new methodology for vendor selection and supply quotas determination to solve specific problems, which would be more objective and easier to use compared to previously used methodologies. There are criteria which by their nature can be complex (they have a hierarchical structure with a number of sub-criteria, sub-criteria have their sub-subcriteria, etc.). It has been shown that these criteria can be simplified by the application of AHP method or the revised weighting method (Peric and Babic 
(2009), Perić, Babić and Veža (2013)). This causes a multi-criteria problem with three objective functions: cost, quality and reliability. When the number of objective functions is greater than 2, for the decision-maker is not easy to choose the preferred solution. The problem becomes more complex when the number of DMs is greater than one. In the situations when in the problem solving participate several DMs we suggest developing the process of the preferred solution choosing according to the idea of cooperative games. The process of problem solving develops through a finite number of steps by solving an integer linear programming (ILP) problem in each step. The solving process is finished when all DMs are satisfied with the obtained solution.

The rest of the paper is organized as follows: The methodology of vendor selection and determination of supply quotas by revised weighting method, and the MP method is presented first. Then the proposed methodology is tested on the real vendor selection problem by a bakery. The advantages of using the proposed methodology in comparison to the use of similar methodologies are emphasized in the conclusion.

\section{Methodology of Vendor Selection and Determination of Supplied Quantity}

For vendor selection and determination of supply quotas we use the revised weighting method, and MP method. The revised weighting method is used to determine the coefficients of complex criteria functions. The main steps in the proposed model are:

1. Determining criteria for vendor selection,

2. Applying revised weighting method to determine the variables' coefficients in the complex criteria functions,

3. Building and solving the MOILP model to determine marginal solutions,

4. Solving the MOILP model by using the MP method to get the preferred solution of the problem.

\section{Determining criteria for vendor selection}

The first step in the proposed methodology is selection of criteria for vendor selection. Numerous criteria are stated in literature and their selection depends on the particular problem (Weber et al, 1991). The total purchasing costs in a particular period, product quality offered by particular vendors, and vendor reliability should be noted as the most important criteria for vendor selection. Each of these criteria is expressed through a number of sub-criteria, which can further be expressed through a number of sub-sub-criteria, etc. This reveals the hierarchical structure of criteria for vendor selection, which enables the application of the revised weighting method to solve the problem of complexity criteria functions (Koski and Silvennoinen (1987)).

\section{The revised weighting method}

The main idea of the weighting method as presented by Gass and Satty (1955) and Zadeh (1963) is to relate each criteria function with the weighting coefficient and to maximize/minimize the weighted sum of the criteria. In that way the model containing several criteria functions is transformed into the model with one criteria function. It is assumed that the weight coefficients $w_{k}$ are real numbers so that $w_{k} \geq 0$ for all $k=1, \ldots, K$. It is also assumed that the weights are normalized, so that $\sum_{k=1}^{K} w_{k}=1$. Analytically presented, the multi-criteria model is modified into a monocriterion model and is called the weighting model: 
$\max _{x \in S} / \min _{x \in S} \sum_{k=1}^{K} w_{k} f_{k}(x)=\sum_{k=1}^{K} \sum_{j=1}^{n} w_{k} c_{k j} x_{j}$

where

$$
S=\left\{x \in R^{n}: x \geq 0, A x<=>b, A \in R^{m \times n}, b \in R^{m} .\right\}, w_{k} \geq 0 \text { for all } k=1, \ldots, K, \sum_{k=1}^{K} w_{k}=1 .
$$

To make the weighting coefficients $w_{k}$ express the relative importance of criteria functions $f_{k}$ a linear transformation of criteria functions coefficients has been proposed (Perić and Babić (2009)). To allow addition of weighted criteria functions we have to transform all of them either into functions that have to be maximized or into functions to be minimized. Linear transformation of criteria functions coefficients that have to be maximized is performed in the following way:

$$
c_{k j}=c_{k j} / c_{k}^{*},
$$

where $c_{k}^{*}=\max _{j} c_{k j}$. Obviously $0 \leq c_{k j} \leq 1$.

The criteria functions that have to be minimized will be transformed into functions to be maximized by taking reciprocal values of coefficients $c_{k j}: 1 / c_{k j}$. Then

$$
c_{k j}^{\prime}=\frac{1 / c_{k j}}{\max _{j}\left(1 / c_{k j}\right)}=\frac{\min _{j} c_{k j}}{c_{k j}}=\frac{c_{k}^{\min }}{c_{k j}} .
$$

Now we will normalize the coefficients $c_{k j}$, so that their sum equals one.

$$
c_{k j}^{\prime \prime}=\frac{c_{k j}^{\prime}}{\sum_{j=1}^{n} c_{k j}^{\prime}}, \quad k=1, \ldots, K .
$$

The previous transformations allow obtaining the weighted sum of criteria functions in which the weights reflect the relative importance of criteria functions.

In this paper we will use the revised weighting method to reduce the complex criteria functions. According to this method, the normalized original criteria functions are divided into groups so that the linear combination of criteria functions in each group forms a new criteria function while the linear combination of new criteria functions form a further criteria function, etc. In this way we obtain a model with a reduced number of criteria functions. According to this each Pareto optimal (efficient)I solution of the new model is also Pareto optimal solution of the original model (Hwang and Masud (1979), p. 243-250).

\section{Multiple objective linear programming (MOLP) model}

The general form of MOLP can be presented in the following way:

If $z_{k}(x)=c_{k} x, \quad x \in R^{n}, c_{k} \in R^{n}$, then

$$
\max _{x \in S} z_{k}(x), k=1,2, \ldots, K,
$$

where $S=\left\{x \in R^{n}: x \geq 0, A x<=>b, A \in R^{m \times n}, b \in R^{m} \cdot\right\}$

Thus, the model (5) contains $K$ linear functions and $m$ constraints, with the variables which must be greater or equal to zero. The variables of the model can be continuous, integer and binary or their combination.

Solving the model (5) so that each of the objective function is separately maximized gives marginal solutions of this model. Since the objective functions in MOLP models are mutually conflicting, the values of objective functions will be significantly different for marginal solutions. 
DMs almost certainly will not choose any of the obtained marginal solutions, but will look for a compromise solution which will satisfy their preferences to objective function values.

To find compromise solution we can use a number of standard multiple objective programming (MOP) methods (see Hwang and Masud, 1979). However, those methods have different efficiency and give different solutions, so the problem of choosing the appropriate method may occur.

\section{A new iterative method for solving MOLP models (MP method)}

For solving MOLP problems with more DMs a new iterative method has been proposed in Matejaš and Perić (2014). This method is based on the idea of cooperative game theory (Osborne, 2003) and significantly helps the DMs in the process of obtaining and choosing the preferred solution.

The MP method ensures finding the preferred efficient solution of the MOLP model with more DMs. Solving MOLP problems by using MP method is carried out through a finite number of steps. Each step includes three stages.

Stage 1. For MOLP problem

$$
\max _{x \in S} z_{k}(x), k=1,2, \ldots, K,
$$

where $S=\left\{x \in R^{n}: x \geq 0, A x<=>b, A \in R^{m x n}, b \in R^{m}\right\}$, for player $\mathrm{P}_{k}$ the acceptable level $r_{k}$ of the $k$ th objective function is specified by players. Then the acceptable budget,

$$
D=\left\{x \in R^{n}: z_{k}(x) \geq r_{k}, k=1,2, \ldots, K\right\}
$$

and the shifted acceptable budget,

$$
D_{\lambda}=\left\{x \in R^{n}: z_{k}(x) \geq \lambda r_{k}, \lambda \geq 0, k=1,2, \ldots, K\right\} \text { is defined. }
$$

Stage 2. Now the smallest $\lambda$ such that $D_{\lambda} \cap S$ is a nonempty set is found, or equivalently the problem

$$
\max _{(x, \lambda) \in V} \lambda
$$

where $V=\left\{(x, \lambda): x \in S, \lambda \geq 0, z_{k}(x) \geq \lambda r_{k}, k=1,2, \ldots, K\right\}$.

is solved. Since $V \in R^{n+1}$ is closed, convex and bounded set, problem (6) has the unique solution $\lambda^{*}$. Solving the problem (6) represents a basic step of the iterative method intended for solving the initial problem (5). This stage can be repeated until the satisfactory solution is attained.

Stage 3. The indicators $\lambda_{k}$,

$$
\lambda_{k}=\frac{z_{k}\left(x^{*}\right)}{r_{k}}, \quad k=1,2, \ldots, K
$$

are defined. They show to what extent the acceptable level $r_{k}$ of the player $\mathrm{P}_{k}$ can be realized.

If the players are satisfied with the obtained solution then "the game is over". If not, then they need to define a strategy for the next step, in which the solution will be improved. Here strategy means the way how to define the initial objective function levels for the next step. The indicators $\lambda_{k}$ help players to choose the right strategy which will ensure desired improvements. The initial data may be redefined in two possible ways. The player $\mathrm{P}_{k}$ can define:

1. New aspiration level $r_{k}$. The constraint $z_{k}(x) \geq \lambda r_{k}$ participates in definition of $D_{\lambda}$ for the next step.

2. Absolute level $g_{k}$. Now, the constraint $z_{k}(x) \geq g_{k}$ enters into the constraint set $S$ and $\mathrm{P}_{k}$ does not participate in definition of $D_{\lambda}$. She is "out of game" because 
she will surely realize at least $g_{k}$. The strategies for the following steps are left to $K-1$ players.

Any choice that $\mathrm{P}_{k}$ chooses have to be approved by other players. Thus, the strategy can be realized by the cooperation among the players or by the rules of regulatory subject, if such one exists.

The main conclusions which could be used as recommendations and principles for creating the "game strategy" are given here.

$\circ$ If the indicator is the optimal one $\left(\lambda_{k}=\lambda^{*}\right)$ then it means that the demand of $k$ th objective function is too high relative to the others. If someone is not satisfied, that is because the demand limits her. To change the situation the demand has to be reduced.

- Any increase of the demand would disable the others to receive more.

- Any decrease of the demand would enable the others to receive more.

- If the others, particularly those whose indicators are not greater than the demand of kth objective function, reduce their demands then the kth player would expect to receive more.

- If the others increase their demands then the kth player would expect to receive less.

- Reduction of the kth indicator in the subsequent steps shows that the demands become too sharp.

We clearly see that the benefits of the other players depend on the kth decision and vice versa. This is the inherent property of this method (Matejaš and Perić, 2014).

Thus, the aim of MP method is to find such efficient solution of (5) which is preferred by all players.

\section{Case study}

\section{Criteria for vendor selection}

Vendor selection and determination of quantities supplied by the selected vendors is a multi-criteria problem. A large number of criteria that can be used in vendor selection is offered in literature. Which criteria will be chosen by the DM depends on the kind of problem to be solved. In this study we will consider criteria that can be used by producers of bakery products when selecting flour vendors. More about the criteria can be seen in Perić, Babić and Veža (2013).

\section{Data required for vendor selection and determination of supply quotas}

Here we will present the example of vendor selection for a bakery. It is to be noted that in production of bread and bakery products the purchase of flour is contracted for the period of one year, from harvest to harvest, which usually does not correspond to the calendar year. After the harvest flour producers have the information on the available wheat quantity, price and quality which allows them to define the price, quality and quantity of flour they can supply in the subsequent oneyear period (Perić, Babić and Veža (2013)).

In the one-year period the bakery plans to consume 6000 tons of flour Type 550. The company contacts 6 potential flour suppliers and defines the upper limit of flour supplied by a single vendor in the amount of 4000 tons. The management have decided to sign a contract of delivery with at least two suppliers. Besides, they decided that the number of suppliers may not exceed four. The proposed prices of flour and transportation costs (Criterion $\mathrm{Cl}$ ) are shown in Table 1. The potential vendors supply data on flour quality which they have to maintain throughout the 
contract period (Criterion C2). It is to be noted that the quality of flour depends on the wheat sort and quality and on technology used in flour production. The vendors should also supply data on their reliability in an appropriate form (Criterion C3). Tables 2 and 3 indicate flour quality and vendor reliability. The weights expressing the relative importance of criteria and sub-criteria are given in brackets, and are determined by the DM where in every group of sub-criteria the sum of weights is 1 .

Table 1

Purchasing costs for flour Type 550

\begin{tabular}{lccc}
\hline Vendor & $\begin{array}{c}\text { Purchasing price } \\
\text { in Euros/ton (B1) }\end{array}$ & $\begin{array}{c}\text { Transportation cost } \\
\text { in Euros/ton (B2) }\end{array}$ & $\begin{array}{c}\text { Total purchasing } \\
\text { costs per ton in Euros }\end{array}$ \\
\hline $\mathbf{1}$ & 240 & 20 & 260 \\
$\mathbf{2}$ & 215 & 25 & 240 \\
$\mathbf{3}$ & 230 & 20 & 250 \\
$\mathbf{4}$ & 275 & 15 & 290 \\
$\mathbf{5}$ & 200 & 10 & 210 \\
$\mathbf{6}$ & 260 & 35 & 295 \\
\hline \multicolumn{5}{l}{ Source: The vendors' offer }
\end{tabular}

Table 2

Quality indicators for flour Type 550

\begin{tabular}{|c|c|c|c|c|c|c|c|}
\hline \multirow[t]{2}{*}{ Quality indicators } & \multirow{2}{*}{$\begin{array}{l}\text { Criteria } \\
\text { weights }\end{array}$} & \multicolumn{6}{|c|}{ Vendor } \\
\hline & & 1 & 2 & 3 & 4 & 5 & 6 \\
\hline $\begin{array}{l}\text { General characteristics of } \\
\text { flour (A1) }\end{array}$ & $(0.20)$ & & & & & & \\
\hline Moisture in \% (B3) & $\min _{(0.30)}$ & 14.2 & 14.56 & 13.6 & 14.1 & 13.09 & 14.85 \\
\hline Ash in \% (B4) & $\min (0.20)$ & 0.56 & 0.55 & 0.59 & 0.51 & 0.54 & 0.48 \\
\hline $\begin{array}{l}\text { Acidity level in } \mathrm{ml} / 100 \\
\text { grams (B5) }\end{array}$ & $\begin{array}{l}\min \\
(0.10)\end{array}$ & 1.8 & 1.8 & 1.6 & 1.8 & 1.5 & 1.5 \\
\hline Wet gluten in \% (B6) & $\begin{array}{l}\max \\
(0.40)\end{array}$ & 26.5 & 26.8 & 29.4 & 24.6 & 24.7 & 28.7 \\
\hline Farinograph (A2) & $(0.30)$ & & & & & & \\
\hline Water absorption in \% (B7) & $\begin{array}{l}\max \\
(0.40)\end{array}$ & 60.2 & 56.3 & 57 & 56 & 57.8 & 55.8 \\
\hline $\begin{array}{l}\text { Degree of mellowness in FJ } \\
\text { (B8) }\end{array}$ & $\min _{(0.60)}$ & 55 & 30 & 33 & 40 & 80 & 50 \\
\hline Extensigraph (A3) & $(0.30)$ & & & & & & \\
\hline Energy $\mathrm{u} \mathrm{cm}^{2}$ (B9) & $\begin{array}{l}\max \\
(0.40)\end{array}$ & 110 & 102.1 & 128 & 104.3 & 98 & 133 \\
\hline Elasticity in mm (B10) & $\begin{array}{l}\max <190 \\
(0.30)\end{array}$ & 163 & 146 & 167 & 161 & 175 & 165 \\
\hline Resistance (B 11) & $\min (0.30)$ & 380 & 400 & 605 & 390 & 330 & 395 \\
\hline Amylograph (A4) & $(0.20)$ & & & & & & \\
\hline Peak viscosity in BU (B12) & $\begin{array}{l}\max \\
(1.00)\end{array}$ & 1110 & 1015 & 1255 & 1610 & 1126 & 1460 \\
\hline
\end{tabular}

Source: Vendors' flour analysis 
Table 3

Vendor reliability indicators

\begin{tabular}{|c|c|c|c|c|c|c|c|}
\hline \multirow[t]{2}{*}{ Reliability indicators } & \multirow[t]{2}{*}{ Criterion } & \multicolumn{6}{|c|}{ Vendor } \\
\hline & & 1 & 2 & 3 & 4 & 5 & 6 \\
\hline $\begin{array}{l}\text { Financial stability, } \\
\text { indebtedness } \\
\text { and liquidity (A5) }\end{array}$ & $(0.60)$ & & & & & & \\
\hline $\begin{array}{l}\text { Coverage of fixed assets and } \\
\text { stocks by capital and long } \\
\text { term resources, (B13) }\end{array}$ & $\max (0.20)$ & 1.15 & 0.90 & 0.85 & 0.80 & 0.99 & 1.18 \\
\hline $\begin{array}{l}\text { Share of capital in source of } \\
\text { funds in \%, (B14) }\end{array}$ & $\max (0.10)$ & 51.46 & 20.7 & 41.0 & 55.77 & 40.2 & 37.6 \\
\hline $\begin{array}{l}\text { Indebtedness factor, number } \\
\text { of years (B15) }\end{array}$ & $\operatorname{Min}(0.10)$ & 8 & 20 & 15 & 16 & 12 & 15 \\
\hline $\begin{array}{l}\text { Total assets turnover } \\
\text { coefficient (B16) }\end{array}$ & $\max (0.10)$ & 0.68 & 0.50 & 0.55 & 0.40 & 0.45 & 0.60 \\
\hline $\begin{array}{l}\text { General liquidity coefficient } \\
\text { (B17) }\end{array}$ & $\max (0.30)$ & 7.25 & 1.2 & 1.15 & 0.85 & 3.13 & 1.70 \\
\hline $\begin{array}{l}\text { Short term receivables } \\
\text { collection period, in days (B18) }\end{array}$ & $\min (0.20)$ & 95 & 111 & 92 & 69 & 80 & 87 \\
\hline Performance indicators (A6) & $(0.40)$ & & & & & & \\
\hline $\begin{array}{l}\text { Coefficient of total revenue } \\
\text { and expenditure ratio (B19) }\end{array}$ & $\max (0.20)$ & 1.07 & 1.04 & 1.03 & 1.01 & 1.02 & 1.05 \\
\hline $\begin{array}{l}\text { Share of profit in total income } \\
\text { in \% (B20) }\end{array}$ & $\max (0.30)$ & 3.95 & 1.55 & 2.34 & 1.12 & 2.10 & 1.80 \\
\hline $\begin{array}{l}\text { Share of profit in assets in \% } \\
\text { (B21) }\end{array}$ & $\max (0.20)$ & 3.28 & 0.99 & 1.45 & 1.05 & 1.30 & 1.05 \\
\hline $\begin{array}{l}\text { Profit per employee in Euros } \\
\text { (B22) }\end{array}$ & $\max (0.30)$ & 7405 & 2560 & 1383 & 1705 & 2260 & 4206 \\
\hline
\end{tabular}

Source: Croatian Financial Agency (Fina)

\section{Application of revised weighting method}

Considering the data from the Tables 1, 2 and 3 we form a hierarchical structure of goals and criteria for vendor selection. The hierarchical structure is shown in Figure 1.

The hierarchical structure in our example consists of five levels as shown in the Figure 1. Level 1 represents the vendor general efficiency (or total value of purchasing - TVP), Level 2 represents criteria for vendor selection, Level 3 represents sub-criteria of criteria from level 2, Level 4 represents sub-criteria of the sub-criteria from level 3, and Level 5 represents the available alternatives (vendors).

After the decomposition of the problem and formation of the hierarchical structure of goals and criteria, we have applied a revised weighting method to calculate the coefficients of cost, quality and reliability functions. By application of the relation (3) and (4) the cost function coefficients are normalized (the cost function that have to be minimized is transformed into the function to be maximized). The following weights are obtained: 
Table 4

Normalized coefficients of cost function

\begin{tabular}{lll}
\hline Variable & Coeff. $c_{i 1}^{\prime}$ & Coeff. $c_{i 1}^{\prime \prime}$ \\
\hline $\mathbf{x}_{1}$ & 0.807692 & 0.162884 \\
$\mathbf{x}_{2}$ & 0.875000 & 0.176458 \\
$\mathbf{x}_{3}$ & 0,839999 & 0.169399 \\
$\mathbf{x}_{4}$ & 0.724137 & 0.146034 \\
$\mathbf{x}_{5}$ & 1.000000 & 0.201666 \\
$\mathbf{x}_{6}$ & 0.711864 & 0.143559 \\
\hline
\end{tabular}

Note: $x_{j}(j=1, \ldots, 6)$ are total quantities supplied by $j$ th vendor.

Source: Author's calculation

Figure 1

Hierarchical Structure of the Vendor Selection Problem

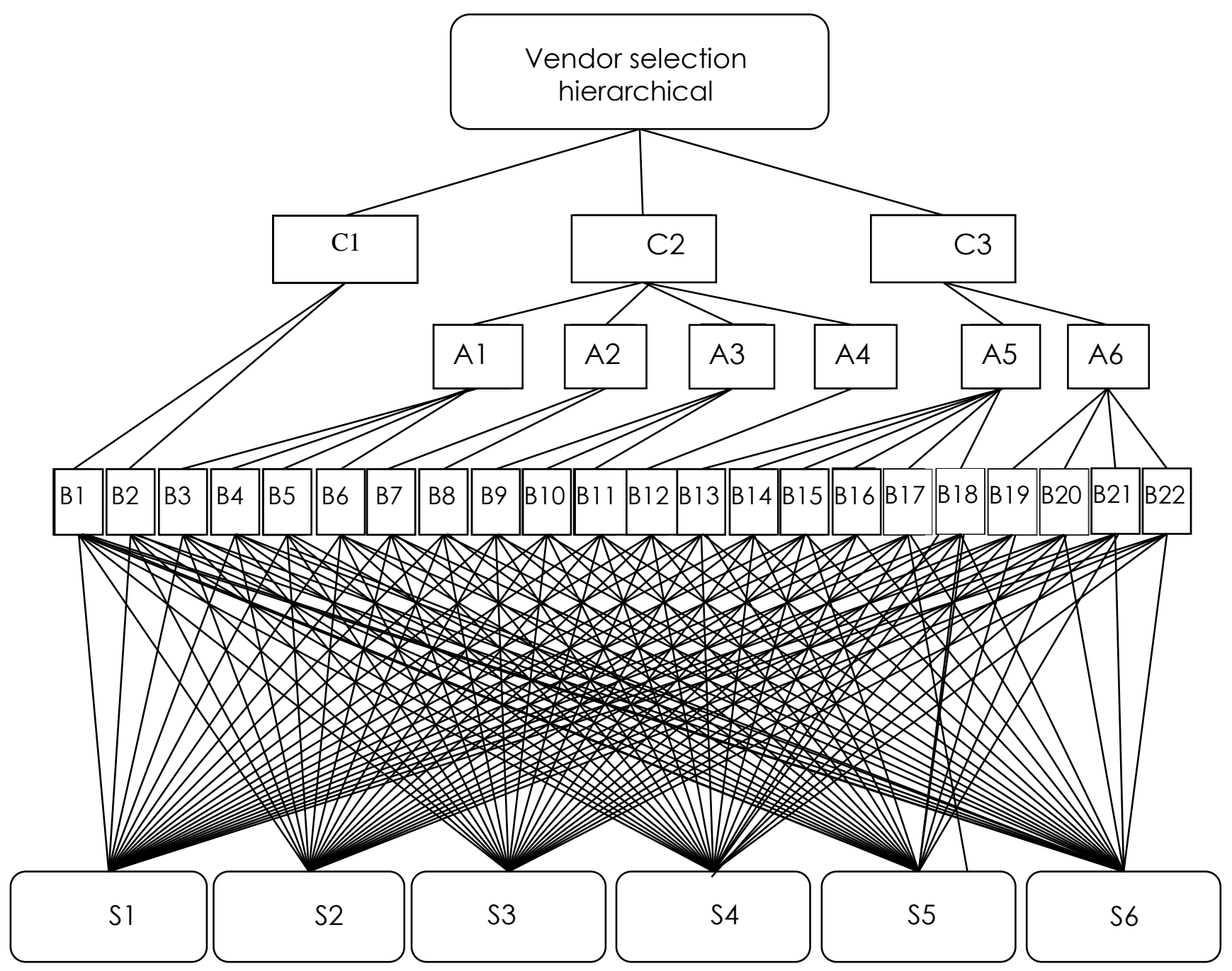

Source: Author's illustration 
The quality function has a hierarchical structure and has to be maximized. Subcriteria B3 to B12 are grouped into 4 sub-criteria sets. According to the data on coefficients weights, their linear transformation and normalization into the interval $[0,1]$ is carried out. The normalized coefficient values are shown in the following table:

Table 5

Normalized coefficient values with variables for sub-criteria B3-B12

\begin{tabular}{lllllllllll}
\hline Var. & $c_{i B 3}^{\prime \prime}$ & $c_{i B 4}^{\prime \prime}$ & $c_{i B 5}^{\prime \prime}$ & $c_{i B 6}^{\prime \prime}$ & $c_{i B 7}^{\prime \prime}$ & $c_{i B 8}^{\prime \prime}$ & $c_{i B 9}^{\prime \prime}$ & $c_{i B 10}^{\prime \prime}$ & $c_{i B 11}^{\prime \prime}$ & $c_{i B 12}^{\prime \prime}$ \\
\hline x1 & 0.164812 & 0.158237 & 0.153257 & 0.164904 & 0.175459 & 0.130506 & 0.162866 & 0.166837 & 0.178565 & 0.146515 \\
x2 & 0.160737 & 0.162132 & 0.153257 & 0.16677 & 0.164092 & 0.23926 & 0.15117 & 0.149437 & 0.169637 & 0.133976 \\
x3 & 0.172083 & 0.15114 & 0.172414 & 0.18295 & 0.166132 & 0.21751 & 0.189517 & 0.170931 & 0.112157 & 0.165655 \\
x4 & 0.165981 & 0.17658 & 0.153257 & 0.15308 & 0.163218 & 0.179445 & 0.154427 & 0.16479 & 0.173987 & 0.212513 \\
x5 & 0.178788 & 0.165135 & 0.183908 & 0.153703 & 0.168464 & 0.089723 & 0.145099 & 0.17912 & 0.193871 & 0.148627 \\
x6 & 0.157598 & 0.185776 & 0.183908 & 0.178594 & 0.162635 & 0.143556 & 0.19692 & 0.168884 & 0.171784 & 0.192714 \\
\hline
\end{tabular}

Source: Author's calculation

Using the data on weighting coefficients with variables of grouped sub-criteria and weighting coefficients with sub-criteria $A 1, A 2, A 3$ and A4, and by applying the relation (1) we calculate the coefficients with criterion $C 2$ variables:

Table 6

Normalized coefficient weights with quality criterion variables

\begin{tabular}{ll}
\hline Variable & Coeff. $c_{i 2}^{\prime \prime}$ \\
\hline $\mathbf{x}_{1}$ & 0.156995 \\
$\mathbf{x}_{2}$ & 0.168946 \\
$\mathbf{x}_{3}$ & 0.174893 \\
$\mathbf{x}_{4}$ & 0.175744 \\
$\mathbf{x}_{5}$ & 0.150379 \\
$\mathbf{x}_{6}$ & 0.173042 \\
\hline
\end{tabular}

Source: Author's calculation

Reliability criterion coefficients are calculated in a similar way:

Table 7

Normalized coefficient weights with reliability criterion variables

\begin{tabular}{ll}
\hline Variable & Coeff. $c_{i 3}^{\prime \prime}$ \\
\hline $\mathbf{x}_{1}$ & 0.289853 \\
$\mathbf{x}_{2}$ & 0.120299 \\
$\mathbf{x}_{3}$ & 0.13347 \\
$\mathbf{x}_{4}$ & 0.122782 \\
$\mathbf{x}_{5}$ & 0.164508 \\
$\mathbf{x}_{6}$ & 0.169088 \\
\hline
\end{tabular}

\section{MOILP model building and solving}

We must first form a MOILP model with three objective functions and nineteen constraints. Considering the data on normalized coefficient weights with variables of cost, quality, and reliability functions, the total demand for flour in the given period, limited quantities supplied by single vendors and the constraint of the minimal and maximal number of vendors, the following MOILP model is formed: 
$\max _{x \in S} z_{1}=0.162884 x_{1}+0.176458 x_{2}+0.169399 x_{3}+0.146034 x_{4}+0.201666 x_{5}+0.143559 x_{6}$ (8)

$\max _{x \in S} z_{2}=0.156995 x_{1}+0.168946 x_{2}+0.174893 x_{3}+0.175744 x_{4}+0.150379 x_{5}+0.173042 x_{6}$ (9)

$\max _{x \in S} z_{3}=0.289853 x_{1}+0.120299 x_{2}+0.133471 x_{3}+0.122782 x_{4}+0.164508 x_{5}+0.169088 x_{6}$. (10) where $S=\left\{\begin{array}{l}(x, y): \sum_{j=1}^{6} x_{j}=6000 ; x_{j} \leq 4000, x_{j} \leq M \cdot y_{j} \\ -x_{j}+M \cdot y_{j} \leq M-x_{j}^{\min }, 2 \leq \sum_{j=1}^{6} y_{j} \leq 4 ; j=1,2, \ldots, 6 ; \\ x_{1}, x_{2}, x_{3}, x_{4}, x_{5}, x_{6} \geq 0 ; y_{1}, y_{2}, y_{3}, y_{4}, y_{5}, y_{6} \in\{0,1\}\end{array}\right\}$.

$z_{1}, z_{2}$ and $z_{3}$ represent purchasing costs, product quality and vendor reliability objective functions, while the set $S$ includes: total needed flour quantity, limited quantities supplied, vendor number constraints, and non-negativity of variables. $y_{j}$ are artificial binary variables and they show us whether supplier $j$ has been chosen. These variables are related to variables $x_{j}$, in such way that if the problem solution contains variable $x_{j}$, then variable $y_{j}$ must equal 1 , and if in the problem solution variable $x_{j}$ is zero then $y_{j}$ must also be zero, and vice versa. $M$ is a very big number, and $x_{j}^{\min }(j=1,2, \ldots, 6)$ is the minimal value which a variable $x_{j}$ can have if a variable $y_{j}$ is included in the solution. In our case $x_{j}^{\min }=2000$.

Model (8)-(10) is a multi-objective integer linear programming model where the coefficients of the objective functions are obtained in the first stage of problem solving by application of the revised weighting method.

Model (8)-(10) is first solved by linear integer programming method, using Lingo 61 software, optimizing separately of each of the three objective functions on the given set of constraints. The results are given in the Payoff table:

Table 8

Payoff values

\begin{tabular}{llll}
\hline Solution & $\mathbf{z}_{1}(\mathbf{x})$ & $\mathbf{z}_{2}(\mathbf{x})$ & $\mathbf{z}_{3}(\mathbf{x})$ \\
\hline$X_{1}{ }^{*}\left(\max z_{1}\right)$ & 1159.58 & 939.408 & 898.630 \\
$X_{2}{ }^{*}\left(\max z_{2}\right)$ & 922.935 & 1052.762 & 758.068 \\
$X_{3}{ }^{*}\left(\max z_{3}\right)$ & 938.654 & 973.704 & 1497.588 \\
\hline
\end{tabular}

Source: Author's calculations

It can be seen that the obtained solutions differ and that DMs have to choose a compromise solution. This work for vendor selection and determination of supply quotas proposes methodology which uses the MP method which is based on the idea of game theory.

Solving the problem by applying the MP method starts informing the DMs (players) $P_{k}(k=1, \ldots, K)$ with the maximal and minimal values of the objective functions. 


$$
\begin{aligned}
& 939.408 \leq Z_{2} \leq 1052.762 \\
& 758.068 \leq Z_{3} \leq 1497.588
\end{aligned}
$$

The DMs should determine the acceptable value of their objective function. The DMs in the first stage have determined the following acceptable value for their objective function: $z_{1}=1100, z_{2}=1040, z_{3}=1200$. It is normal that each DM wants to achieve the highest value possible for their objective function. At the beginning the DMs know that they can severely achieve the determined acceptable level of their objective function in the first step. The final acceptable level of the objective function values will be achieved after several steps of the method application, which requires active participation of the DMs and negotiation in the process of problem solving.

In the second stage of the method the following integer linear programming model is solved:

$$
\max _{(x, \lambda) \in V} \lambda
$$

$$
\text { where } V=\left\{\begin{array}{l}
(x, y, \lambda): \sum_{j=1}^{6} x_{j}=6000 ; x_{j} \leq 4000, x_{j} \leq M \cdot y_{j} \\
-x_{j}+M \cdot y_{j} \leq M-x_{j}^{\min }, j=1,2, \ldots, 6 ; 2 \leq \sum_{j=1}^{6} y_{j} \leq 4 ; z_{1} \geq 1100 \lambda ; \\
z_{2} \geq 1040 \lambda ; z_{3} \geq 1200 \lambda ; x_{1}, x_{2}, x_{3}, x_{4}, x_{5}, x_{6} \geq 0 ; y_{1}, y_{2}, y_{3}, y_{4}, y_{5}, y_{6} \in\{0,1\}
\end{array}\right\}
$$

The following solution has been obtained:

Table 9

The solution of stage 2, step 1

\begin{tabular}{llllllll}
\hline Solution & Variable values & $\mathbf{z}_{1}$ & $\mathbf{z}_{2}$ & $\mathbf{z}_{3}$ & $\lambda_{1}$ & $\boldsymbol{\lambda}_{2}$ & $\boldsymbol{\lambda}_{3}$ \\
\hline $\mathrm{I}$ & $\mathrm{x}_{1}=2349.75, \mathrm{x}_{2}=$ & 1026.852 & 985.383 & 1120,204 & 0.93 & 0.95 & 0.93 \\
& $3650.25, \mathrm{x}_{3}=0, \mathrm{x}_{4}$ & & & & & & \\
& $=0, \mathrm{x}_{5}=0, \mathrm{x}_{6}=0$, & & & & & \\
& $\lambda=0.933502$ & & & & & & \\
\hline
\end{tabular}

Note: The indicators $\lambda_{k}(k=1,2,3)$ are calculated using (7).

Source: Author's calculations

None of the DMs was satisfied with the obtained solution.

The second step of the method begins with the determining reduced aspiration levels. The DMs agreed to determine: $r_{1}=1050, r_{2}=1020, r_{3}=1100$.

After solving the model (14) with the changed constraints $z_{1} \geq 1050 \lambda$ instead of $z_{1} \geq 1100 \lambda, \quad z_{2} \geq 1020 \lambda$ instead of $z_{2} \geq 1040 \lambda, z_{3} \geq 1100 \lambda$ instead of $z_{3} \geq 1200 \lambda$, the following solution has been obtained: 
Table 10

The solution of stage 2, step 2

\begin{tabular}{|c|c|c|c|c|c|c|c|}
\hline Solution & Variable values & z1 & $\mathrm{z2}$ & $z 3$ & $\lambda_{1}$ & $\lambda_{2}$ & $\lambda_{3}$ \\
\hline II & $\begin{array}{l}x 1=2000, x 2=0 \\
x 3=4000, x 4=0, \\
x 5=0, x 6=0, \\
\lambda=0.95556\end{array}$ & 1003.365 & 1013.382 & 1113.586 & 0.96 & 0.99 & 1.01 \\
\hline
\end{tabular}

Source: Author's calculations

Only the DM1 was not satisfied with the obtained solution.

Step 3. Because the DM 3 is achieved more than the specified acceptance level for the objective function $z_{3}$, the DMs have agreed with $r_{1}=1050, r_{2}=1010$, and $z_{3} \geq$ 1100 , to allow for an increase in the value of the objective function $z_{1}$.

After solving the model (14) with the changed constraints $z_{2} \geq 1010 \lambda$ instead of $z_{2} \geq 1020 \lambda$ and $z_{3} \geq 1100$ instead of $z_{3} \geq 1200 \lambda$ the following solution has been obtained:

Table 11

The solution of stage 2 , step 3

\begin{tabular}{llllllll}
\hline Solution & Variable values & $\mathrm{z}_{1}$ & $\mathrm{z}_{2}$ & $\mathrm{z}_{3}$ & $\lambda_{1}$ & $\lambda_{2}$ & $\lambda_{3}$ \\
\hline III & $\mathrm{x}_{1}=2230.59, \mathrm{x}_{2}=$ & 1028.469 & 986.818 & 1100.00 & 0.98 & 0.99 & 1.00 \\
& $3769.41, \mathrm{x}_{3}=0, \mathrm{x}_{4}$ & & & & & & \\
& $=0, \mathrm{x}_{5}=0, \mathrm{x}_{6}=0$, & & & & & \\
& $\lambda=0.977246$ & & & & & & \\
\hline
\end{tabular}

Source: Author's calculations

The DMs have accepted the obtained solution. Therefore after only three steps the Nash equilibrium solution has been obtained. By this is the solution process completed.

It should be noted that the method supposes that the DMs know acceptable level of their objective functions. In our case the DM 1 and DM 2 achieved the acceptable level of their objective functions after the step 1 and the step 2 respectively. However, to allow the DM 1 to increase her objective function value, the DM 3 had to decrease her objective function acceptable level. If the DM 1 was not satisfied with her objective function level, the DM 1 and DM 2 would negotiate about further decrease of the objective function $z_{2}$ acceptable level. Therefore, the solution process ensures obtaining the preferred efficient solution in minimal number of steps.

To show that the proposed methodology is better than the application of standard MOILP methods in solving this problem, model (8)-(10) has been solved by $\varepsilon$-Constraints MOILP method (Hwang and Masud (1979), p. 250-252)). First, function $z_{1}$ has been maximized, while functions $z_{2}$ and $z_{3}$ are put into the constraints set, gradually reducing the value of the objective functions in the constraint set, then function $z_{2}$ has been maximized with functions $z_{1}$ and $z_{3}$ in the constraints set, gradually reducing their goals, and at the end function $z_{3}$ has been maximized, while the functions $z_{1}$ and $z_{2}$ are included into the constraint set, gradually reducing their goals. In this way a big number of efficient solutions has been obtained. The set of efficient solutions has been presented to the DMs. However, for the DMs it was very difficult to choose the preferred solution. 


\section{Conclusion}

Solving the real vendor selection and supply quotas determination problem by using the proposed methodology we can make a number of conclusions presenting the strengths of the proposed methodology in solving the problem.

The revised weighting method allows efficient reducing of complex criteria functions into simple ones. For DMs, it is easier to determine weighting coefficients if they deal with few criteria functions than if they deal with a large number of them. So if there is a large number of criteria and sub-criteria, there is a higher probability of error in determining the weighting coefficients.

When solving the MOIFP model by using the new method based on game theory the DMs are actively included in the process of finding the preferred solution. If some of the DMs are not satisfied with the obtained solution in the solution process they know where is the 'problem', i.e. who should reduce the aspiration level to allow that unsatisfied DM improve their objective function value. Here DMs choose the preferred solution in the process of negotiation between the DMs and solving an integer linear programming problem through a finite number of steps. Obtained preferred solution is also Nash equilibrium.

Therefore the simplicity of using is the main advantage of the proposed methodology.

Further improvements of the proposed methodology of vendor selection and supply quotas determination problem in terms of dynamic process and simultaneous application of quantity discounts as well as discount of quantity value in a particular period will be the subject of our future research.

\section{References}

1. Gass, S., Satty, T. (1955) "The Computational Algorithm for the parametric Objective Function", Naval Research Logistics Quarterly, Vol. 2, pp. 39-45.

2. Ge Wang, Samuel, H.H., Dismekes, J.P. (2004) "Product driven supply chain selection using integrated multicriteria decision-making methodology", Int. J. Production Economics, Vol. 91, pp. 1-15.

3. Ghodsypour, S.H., O'Brien, C. (1998) "A decision support system for supplier selection using an integrated analytic hierarchy process and linear programming", Int. J. Production Economics, Vol. 56, pp. 199-212.

4. Hwang, C. L., Masud. A. S. M. (1979) Multiple Objective Decision Making: Methods and Applications, Springer Verlag, New York.

5. Koski, J., Silvennoinen, R. (1987) "Norm Methods and Partial Weighting in Multicriterion Optimization of Structures", International Journal for Numerical Methods in Engineering, Vol. 24, No. 6, pp. 1101-1121.

6. Kumar, M., Vrat, P., Shankar, R. (2004) "A fuzzy goal programming approach for vendor selection problem in a supply chain", Computers \& Industrial Engineering, Vol. 46, Issue 1, pp. 69-85.

7. Kumar, M., Vrat, P., Shankar, R. (2005) "A fuzzy goal programming approach for vendor selection problem in a supply chain", Int. J. Production Economics, Vol. 101, pp. 273-285.

8. Kumar, P., Shankar, R., Yadav, S.S. (2008) "An integrated approach of Analytic Hierarchy Process and Fuzzy Linear Programming for supplier selection", Int. J. Operational Research, Vol. 3, No. 6, pp. 614-631. 
9. Matejaš, J., Perić, T. (2014) „A new iterative method for solving multiobjective linear programming problem", Applied Mathematics and Computation, Vol. 243, No. 9, pp. 746-754.

10. Osborne, J. M. (2004) An introduction to game theory, Oxford University Press, New York,

11. Perić, T., Babić, Z. (2010) "Vendor Selection by Application of Revised Weighting Method and Fuzzy Multicriteria Linear Programming", Proceedings of the Challenges for Analysis of the Economy, the Businesses, and Social Progress, International Scientific Conference, Szeged, November 19-21, 2009. www.edoc.hu/conferences/statconf2009, Edited by Peter Kovacs, Katalin Szep and Tamas Katona, Published by Unidocument Kft. www.e-document.hu, Szeged, pp. $1317-1342$.

12. Perić, T., Babić, Z., Veža, I. (2013) "Vendor selection and supply quantities determination in a bakery by AHP and fuzzy multi-criteria programming", International Journal of Computer Integrated Manufacturing, Vol. 26, Issue 9, pp. 816-829.

13. Weber, C.A., Current, J.R., Benton, W.C. (1991) "Vendor selection criteria and methods", European Journal of Operational Research, Vol. 50, pp. 2-18.

14. Zadeh, L. (1963) "Optimality and Non-Scalar-valued Performance Criteria", IEEE Transactions on Automatic Control, Vol. 8, pp. 59-60.

\section{About the author}

Tunjo Perić is an assistant professor at the University of Zagreb, Faculty of Economics and Business, Department for Mathematics, Croatia. His research interests include multiple objective programming methods and applications in economics and business, multiple criteria decision making and applications, cooperative and noncooperative game theory, etc. Author can be contacted at tperic@efzg.hr 